\title{
MONITORING OF COMPLEX DESIGN SYSTEMS OF SPECIAL STRUCTURES
}

\section{Yevhen Gorokhov \\ Dr.Sc., Prof.}

The Donbas National Academy of Civil

Engineering and Architecture (DonNACEA)

2, Derzhavina street, Makeevka, 86123, Donetsk

Region, Ukraine

ksv@dgasa.dn.ua

\section{Volodymyr Vasylev}

PhD., Assoc. Prof.

The Donbas National Academy of Civil

Engineering and Architecture (DonNACEA)

2, Derzhavina street, Makeevka, 86123, Donetsk

Region, Ukraine

ksv@dgasa.dn.ua

\author{
Yaroslav Nazim \\ PhD., Assoc. Prof.
}

The Donbas National Academy of Civil

Engineering and Architecture (DonNACEA)

2, Derzhavina street, Makeevka, 86123, Donetsk

Region, Ukraine

ksv@dgasa.dn.ua

\section{Sergiy Kuznetsov}

PhD., Assoc. Prof.

The Donbas National Academy of Civil

Engineering and Architecture (DonNACEA)

2, Derzhavina street, Makeevka, 86123, Donetsk Region, Ukraine ksv@dgasa.dn.ua

\section{Valentyna Garkusheva \\ Assoc. Prof.}

The Donbas National Academy of Civil Engineering and Architecture (DonNACEA)

2, Derzhavina street, Makeevka, 86123, Donetsk Region, Ukraine

ksv@dgasa.dn.ua

\begin{abstract}
Monitoring of special structures is more and more widely spread to estimate their state while in use. The forecast reliability is conditioned by a quality of the observation program, equipment and apparatuses, by means of processing and analysis of the observation results. For this purpose there was established a Site for testing PTL supports and tower structures. The Ukrainian Site is a unique universal test bed for static and dynamic tests of both separate constructions and a structure in whole with a continuous recording of time-dependent parameters and processing of the signals obtained, and for studying and collecting statistical information on weather changes and micrometeorological peculiarities of nature effects on a specific object. To solve these tasks, there was developed and approved a universal multi parameter informationmeasurement system. Within the Site there was developed and introduced an automated frost-wind weather-station intended for automatic measurement of the environment hydro-meteorological parameters. There was also established an
\end{abstract}


electronic-computing complex to perform full-scaled investigations of wind loads under real conditions of a surrounding housing.

\section{KEYWORDS}

Monitoring, special structures, weather station

\section{OPERATIONAL RELIABILITY DIAGNOSTICS}

A great role in estimating operational reliability, durability, and safety of structures belongs to field testing and long run observation of structures $[1,2]$. It makes a well-grounded diagnosis of structures possible and, when necessary, allows developing measures to increase their reliability.

Monitoring of special structures is more and more widely spread to estimate their state while in use. In the true sense of the word monitoring of structures is observation, analysis, and forecast. Observation therewith provides an instrumental and visual description of load parameters and other effects, as well as static and dynamic behavior of a structure in the large, and its separate components in the space of real loads and effects. Behavior is interpreted here as a structural response to external actions. Analysis means a comparison of actual parameters of loads and effects under field conditions and their design values. This is necessary to specify a probability of external actions and reliability of design models. The forecast of a structure state drawn up on the basis of observation and estimation is of a special importance in monitoring. It gives us good reasons to judge a remaining life of structures and, when necessary, to actively increase reliability on-stream. A confidence level of the forecast is conditioned by the quality of the observational program, instrumentation and equipping, processing means and analysis technique of the observational results.

\section{EXPERIMENTAL VALIDATION OF PTL STRUCTURES}

\subsection{The Site Scheme for Testing PTL Supports and Tower Structures}

Theoretical and pilot researches on the development of new power transmission line (PTL) supports with regard for the international standards, as well as their production and erection can not be carried out without a full-scale testing of pilot models. The Ukrainian Site for testing PTL supports and tower structures which was put into operation in May, 1997 is intended for performing bench static and dynamic tests.

The Site is a unique engineering structure. It is second to none in Ukraine, one of two sites in the CIS, and one of 13 sites in the world. When designing the Site, there were taken into account the tendencies of the development of electrical supply network construction and a possibility to extend its performance characteristics. By most of its engineering performance the DonNACEA Site outproduces the largest sites of Asia (AL-Batain Industries Tower Testing Station, Saudi Arabia) and Europe (Tower Research And Testing Center (CIET, Spain).

The Site comprises a test bench and auxiliary facility (Figure 1).

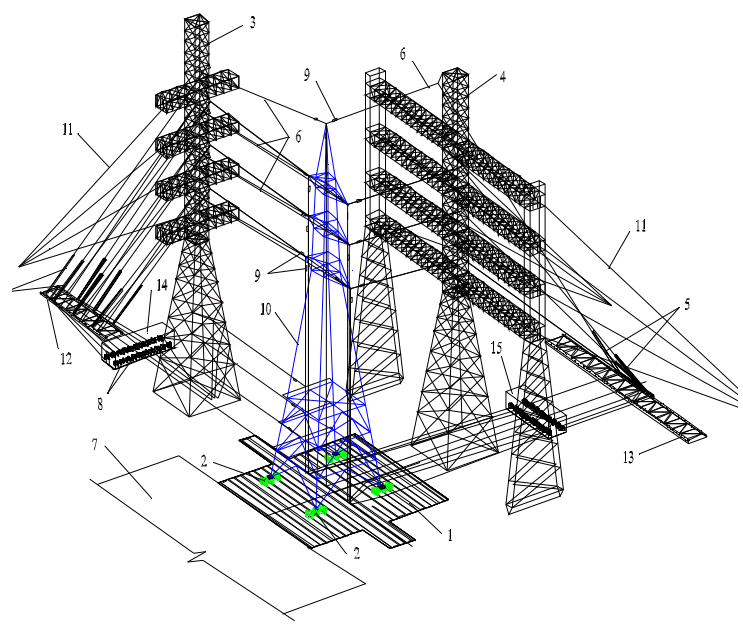

Figure 1. The Site Scheme for Testing PTL Supports and Tower Structures 


\subsection{Characterization of Wind Influence and Structural Response}

To solve the tasks of dynamic tests, there was developed and approved at some industrial enterprises a universal multi-parameter informationmeasurement system (UMPIMS-1) [3, 4] intended for monitoring wind influence on a structure and estimating its response. A distinctive feature of the hardware support is focusing on the form-factors of the IBM-similar personal computers. The hard- and software of the IBM system modules made it possible to develop a multi-channel system of collecting measurement information and the characteristics acceptable for a practical use. The openness of PC architecture determined the openness of the system.

The system basic configuration comprises a computer, a modular interface adapter (MIA) attached to a system bus. The MIA is linked with a measurement module which comprises an allpurpose controlled amplifier, as well as a switching unit and a 64-channel strain-gauge amplifier. The structure of analog switching units, as well as engineering data of a controlled amplifier makes a networking of different measuring transducers possible. The latter include vibration speed gauges, strain-gauge dynamometers, accelerometers etc. To

a)

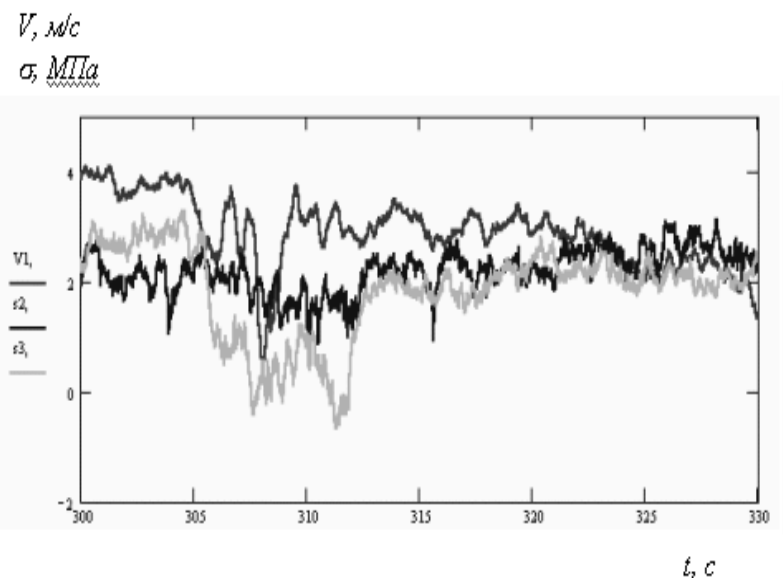

guarantee the measurement of wind velocity in a frequency range compatible with a frequency range of PTL tower vibrations, there was developed a hotwire anemometer optimized for using in open atmosphere.

As an example of experimental investigations let us consider the study of dynamic properties of a PTL intermediate support in the system "support-cables" and determination of this system response to wind influence. In Figure 2 there are given a typical realization of the signals obtained. In Figure 2,a there are shown the diagrams of voltage variations in windward belts at a wind perpendicular to a PTL route, Figure 2,b shows the diagrams of voltage variations in diagonal belts at wind along the PTL.

The amplitude-frequency characteristics of the system were obtained with the help of equation [5]:

$$
A=\frac{1}{\sqrt{\left(\left(1-\left(\frac{F_{p}}{F_{c}}\right)^{2}\right)+\left(2 \cdot \delta \cdot\left(\frac{F_{p}}{F_{c}}\right)^{2}\right)\right)}},
$$

where Fp is a frequency of induced vibrations;

Fc is a frequency of self-induced vibrations.

b)

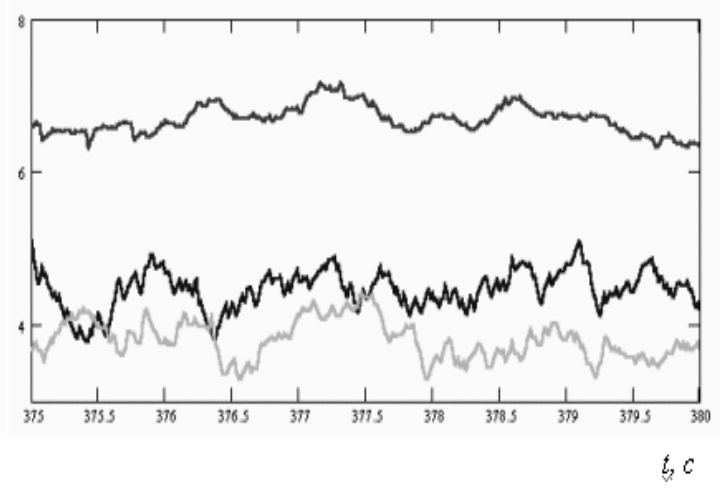

Figure 2. Typical Realization of the Signals Obtained

$\mathrm{V}-$ wind velocity at a height of $10 \mathrm{~m}, \mathrm{~m} / \mathrm{sec}$; $\mathrm{s}$ and $\mathrm{s} 3$ - voltages in belts 


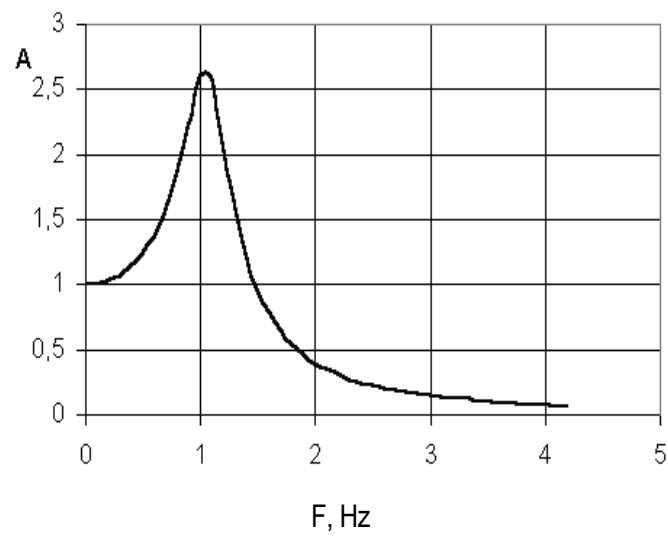

Figure 3. A Tower Amplitude-Frequency Characteristic

So, there were obtained dynamic characteristics of a PTL support and coherence functions of external actions and a structure response Figure 3.

\subsection{An Automated Complex of Test Control}

The control system of support testing to a large extent determines engineering possibilities of the operations performed on the Site and their quality. The basic tasks which are solved by this system in the test operation are monotonic loading control of a support under test; a support loading to a design value when passing through intermediate stages; a maximum decrease of a load duration scheme.

Complexity of solving a task on controlling the loading of a support under test is that all loads applied to the support are interconnected, as one load change results in deformation of the support in the large, and this, in its turn, leads to other loads change.

Taking into account the results of the analysis of the systems of loading and controlling the process of support loading, as well as the field experience of other sites, when designing the DonNACEA Site we developed the control scheme with the help of an automated complex of personal computers which comprised the following subsystems:

- development of a test program (schemes of loading, placement of electrical dynamometers, angles of advance of winch cables);

- calibration of electrical dynamometers;
- control and test of monitoring instrument;

- test control;

- concluding on test results.

All the systems are interconnected and use the common database. Such a scheme of controlling tests allowed creating an effective test bench at minimum material equipment costs; the bench allows testing unique PTL supports. Since 1997 till 2007 there were performed the certified tests of towers as high as 15$62 \mathrm{~m}$ and up to 64 tons in weight for Egypt, Syria, Iceland, Turkey, Iraq, China and other countries.

\subsection{Measurement of Weather Parameters of PTL Operational Environment}

Complexity of metric realization and an essential spread of hydro-meteorological parameters, first of all ice-loading, depending on the area topographical conditions, territory and height of an object location above the ground level made a necessity of developing a departmental net of electrical companies for weather parameters to be monitored.

There was suggested an automated ice-wind weather post (AIWWP) for an automatic measurement of hydro-meteorological parameters of the environment and a further transmission of data to a control centre (Figure 4).

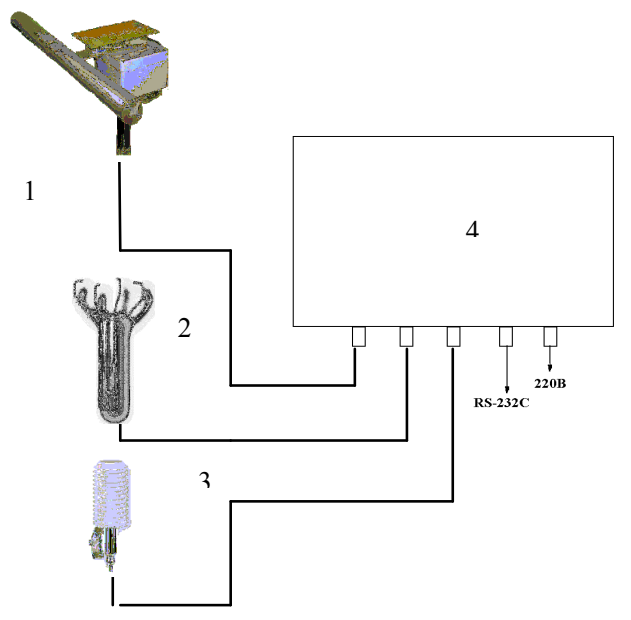

Figure 4. A Weather Post Structure:

1 - a meter of ice weight and sail force; 2 - an ultrasonic wind indicator; 3 - air temperature and moisture meters; 4 - a control block of data transmission 
An AIWWP pilot model being approved in 2004 on the DonNACEA Site, there were installed 4 weather posts in the system of the National Energy Company "Ukrenergo" in Odesa, Ternopil, and Khmel'nitsk regions.

In 2007, because of modernization of the information-management systems of the power supply companies of Ukraine, in order to meet the integration conditions of transducers for measuring weather parameters in the telemechanics company "Korund-M" for a further data transmission into a unique record in a control centre, and to fulfill the conditions of the equipment metrological certification, there were made alterations in the AIWWP structural scheme. By the aggregate-modular principle there was created a weather post of complete functional modules, each of them can be considered as a separate measure, integrated into a single computer-based system of monitoring the process parameters in a real time: an anemometer-rhumb finder MARK-60AF; a multi-channel universal measuring and controlling peripheral processing module TPM138P with temperature, humidity, and thunderhead detectors; a meter of ice coating weight on the base of a ruler of the SCAIME-firm instruments.

\section{INVESTIGATION OF WIND LOADS UNDER ACTUAL DEVELOPMENT CONDITIONS}

In many cities of the world, especially in capitals, there is the rule to have high-technology high-rise buildings which form a memorable look and create accents of urban ares development The up-to-date development of the Ukraininan economics creates favourable conditions for mass construction of such objects. Structural and design parameters of the basic load-bearing members of high-rise buildings greatly depend on wind loading. The task of aerodynamics is to convert an urban aerodynamic situation into the data which can be used in designing. A high degree of approbation of the results obtained is needed. Now, a lot of researchers have accumulated a great number of different data on the investigation of wind loads on high-rise buildings obtained on the base of scaled tests in a wind tunnel. These experimental results as a rule reflect a particular form and arrangement of high-rise buildings.
Model experiments can be properly checked with a full-scale investigation of wind influences in field conditions. The basis of the in-situ measurements of wind pressures is the program of model drainage experimental researches which means a determination of values of nondimensional coefficients of pressure $\mathrm{Cp}$ in the points under study on the external surfaces of a high-rise building:

$C_{p}=1-\frac{\Delta P_{i}}{q_{\infty}}$,

where $\Delta \mathrm{Pi}$ is an excess pressure in the point under study as to atmospheric pressure; q $\infty$ is a ram air over a prototype system:

$q_{\infty}=\frac{\rho V_{\infty}^{2}}{2}$,

where $\rho$ is air density.

When using the obtained values of $\mathrm{Cp}$, wind loads on a building (Figure 5) were determined by the formula:

$P_{i}=\Delta P_{i} \cdot q_{\infty}$.

To correlate a full wind flow $\mathrm{V} \infty$ and pressure on the surface, over a building, there is installed a weather post which generates information about wind velocity and direction, air temperature, pressure, and relative humidity.

To substantiate an anemometer and pressure transducers place over a prototype system, before a fullscaled monitoring there are performed scaled aerodynamic tests in a tunnel to study flow peculiarities.

It is especially important to find out a height of a nonperturbed wind flow for an anemometer. An ideal height of an anemometer arrangement depends on a building cross-section and geometrical shape $[6,7]$.

To carry out field observation, there was developed a computer complex which allows studying wind loads in full-scale conditions. To fix wind pressure, there are used small-sized pressure transducers attached to building surfaces. All the transducers are joined with one common system of data collecting, processing, and mapping. The system consists of a necessary 

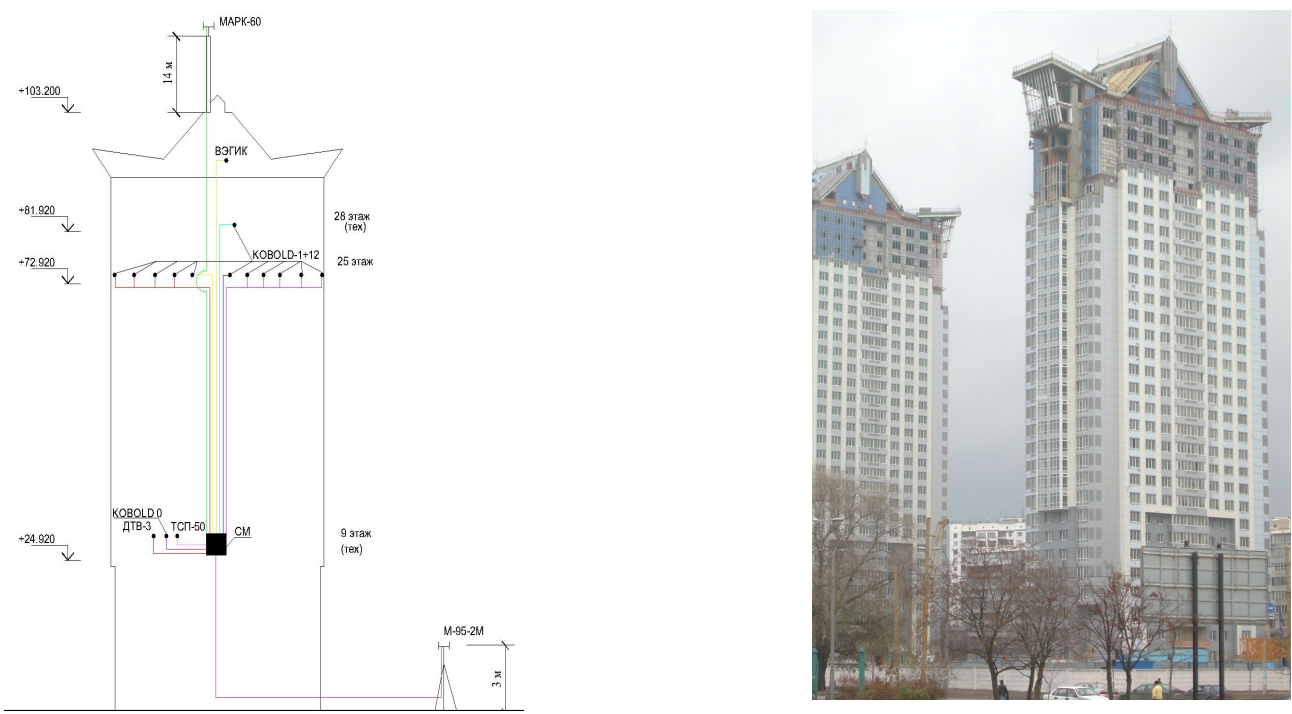

Figure 5 An Example of Carrying out an In-situ Measurement of Wind Influences: a - a scheme of arranging transducers and devices on an object under test; $\sigma-$ a general view of a group of buildings

minimum core and a variable number of measuring and control channels. The system can make an inquiry of the remote transducer array with a given quantization discreteness at a pace of changing controlled variables and produce adequate stimuli by corresponding channels. All data flows have their graphic and tabular representation in a computer. The system is controlled by an instrumental operational software module which allows an online reconfiguration of functions depending on a specific character of a current task (Figure 5).

\section{CONCLUSIONS}

A technical basis of protecting safe operation of high-rise buildings is introduction of control and diagnostic tools [8]. One of such elements of monitoring can be observation of wind influences on high-rise buildings. The state-of-the-art of research developments and engineering solutions let us peak with confidence about a possibility of carrying out field observation of wind parameters and fix wind loads on high-rise building surfaces.

\section{REFERENCES}

[1] Gorokhov, Ye. (1987) Diagnostics, detection of bearing capacity reserves and enhancement of metal structures of industrial buildings under reconstruction , Kiev, 85.

[2] Kazakevich, M. (1987) Bridge aerodynamics, Moscow, 240.

[3] Gorokhov, Ye., Kazakevich, M., Shapovalov, S. and Nazim, Ya. (2000) Aerodynamics of electric net structures, Donetsk, 336 p.

[4] Gorokhov, Ye., Kazakevich, M., Turbin, S. and Nazim, Ya. (2005) Wind and ice influences on overhead power transmission lines, Donetsk, 348.

[5] Germanisher Lloid (1994) Rules and Regulations. IV - Non Marine Technology. Part 1 - Wind Energy. Regulation for the Certification of Wind Energy Conversion Systems. Chapter 1-10.

[6] Cochran, L. and Cermak, J. (1992) Full-scale and model-scale cladding pressures on the Texas-Tech University Experimental Building, Journal of Wind Engineering and Industrial Aerodynamics, Vol. 43, No. 1-3, 1589-1600.

[7] Hoxey, R. and Richards P. (1995) Full-scale wind load measurements point the way forward, Journal of Wind Engineering and Industrial Aerodynamics, Vol. 57(2-3) 215-224.

[8] Milford, R., Gliger A., and Waldeck J. (1992) Jan Smuts experiment - Comparison of full-scale and wind tunnel results, Journal of Wind Engineering and Industrial Aerodynamics, Vol. 43, No. 1-3, 17051716. 